\title{
Larynx Edema, CTCAE
}

National Cancer Institute

\section{Source}

National Cancer Institute. Larynx Edema, CT CAE. NCI Thesaurus. Code C58189.

Laryngeal edema resulting from a known treatment. 